unable to do so. We were fortunate in obtaining such posts and in recetving support from consultants and clinical tutors to realise our plans. Trainees wishing to work part-time should seek advice from the Regional Postgraduate Dean and make sure that their proposed scheme meets the College's prospective approval. It should be possible to arrange some sort of job-sharing if there are two trainees wishing to work part-time. Being a couple is probably an advantage as there will be fewer conflicting interests and it is less likely that one trainee will suddenly want to move. Supernumerary registrar posts are not advertised and one should check availability with regional health authorities. The common view that part-time posts are for women only has probably little to do with the attitude of employers but perhaps more with reluctance among male doctors to enlarge their roles in domesticity. At the time of writing, however, two out of the four supernumerary part-time registrars in Yorkshire are men!

The advantages of part-time trainees to the NHS have been recognised previously (Livingston et al, 1988). Part-time training clearly benefits family-life but the experience of childcare is also highly relevant to the practice of psychiatry. We hope that the
College will actively promote flexdbility in training and careers for both women and men.

\section{Acknowiedgements}

We are grateful to Dr P. C. W. Bowie and Dr D. $J$. Thompson for their comments.

\section{References}

GATH, A. (1988) Part-time senior registrar training in child and adolescent psychiatry. Bulletin of the Royal College of Psychiatrists, 12, 368-370.

LIVINGSTON, H. M., OGELTHORPE, D. \& ROBERTSON, S. (1988) Part-time senior registrar training in psychiatry. A feasible option? Psychiatric Bulletin, 12, 523-525.

RouTH, C. P. (1991) Part-time training in psychlatry: what trainces want. Psychiatric Bulletin, 15, 614-615.

TALBOT, R. (1993) Part-time higher training in child and adolescent psychiatry. Psychiatric Bullettr, 17. 665-666.

*Erik van den Brink, Registrar in Psychiatry, Ingrow Centre for Community Mental Health, 200 South Street, Keighley BD21 1BB; and Anja Sanders, Registrar in Child and Adolescent Psychiatry, Hillbrook Child and Family Unit, Mayfield Road, Keighley BD20 6LD

"Correspondence

\title{
Prince who?: the influence of the mass media on elderly people
}

Rohul Roc examines the role of the Royals in diagnosing dementia.

The recent debate at the Liberal Democrats' Conference in Brighton about a future 'Republic of Britain' may have caused some disquiet among fervent monarchists. No doubt it will also have raised some alarm in the ranks of the current elderly population, in whose hearts the Royal Family appears to hold a very special place.
In screening and diagnosing dementia, for instance, the acquisition and retrieval of recent information is tested by assessing knowledge of current, including royal, affairs. During a recent research project Cambridge residents aged 81 and over were interviewed using the 'CAMCOG', the section of CAMDEX assessing cognitive function. As part of this, the question "What is the name of the present King/Queen?" is followed by "Who will follow him/her?". Out of the 123 subjects interviewed, $17 \%(n=21)$ did not know the 
answer and 10\% (n=12) gave an incorrect reply. However, of the remaining group, only $24 \%(n=30)$ gave the answer "Charles" without further thought. The largest group (49\%, $n=60)$ also gave the correct answer, but pondered over whether or not he should be the heir to the throne. "How can we be so sure?" was a common answer, as was "So much has happened recently, so it should be William".

One striking example of how the popular press influences even the most impaired intellect, was that of an elderly lady with moderate dementia. She lived in a nursing home and was unable to read because of deteriorating eyesight. She had suffered marked personality change, disorientation, grossly impaired short-term memory and inability to give either the dates of the World Wars or name the current Prime Minister or Queen. Nevertheless her answer to the question "Who will follow him/her?" was 'Well, it can't be Charles after all that's been happening, can it?: he's been muckin' around with too many women!".

It has been a frequent observation among geriatricians who use short screens of cognitive function such as the Hodkinson Test (which asks for the name of the present monarch and prime minister), that ten years ago, a substantially higher proportion of elderly people recalled the name of Mrs Thatcher than remembered the name of the monarch.

Research evidence for this came from a study at the Maudsley Hospital, in which a retrospective study of case-notes compared the recall of Prime Ministers' names during the fourth and fifth years of each person's term of office with recall of the monarch. One finding was that Mrs Thatcher's name was remembered more often than those of both $\mathbf{M r}$ Macmillan and Mr Wilson; another was that
Mrs Thatcher's name was recalled more often than that of the Queen. Yet the mean cognitive score for those recalling Mrs Thatcher was significantly lower than for those recalling either of the other two Prime Ministers. The authors concluded that Mrs Thatcher reaches those parts of the brain other Prime Ministers cannot reach!

Perhaps it is not surprising that, among the current elderly population, many of whom hold the Royal Family in high regard, press speculation over the future of the present monarchy is followed closely. It is also evident that cognitive impairment is no obstacle to such awareness. When assessing recent knowledge of current affairs, the influence of the media as a powerful source of communication should always be taken into account; particularly for those news items that are more readily appealing. In this respect, such knowledge may only become apparent when these more 'popular' topics are addressed.

This highlights the limited validity of some screening instruments for dementia when assessing general knowledge. When using retrieval of recent information as part of a bedside test of cognitive function, the clinician should take into account that questions relating to more controversial topics may not be sensitive in distinguishing between demented and non-demented patients.

Even so, with Royals such as Princess Diana now the media's number one news-seller, screening elderly patients with the question "Can you tell me what has been happening in Princess Di's life' recently?" may not help to diagnose dementia. But it will surely provide some interesting answers!

Rahul Rao, Registrar in Psychiatry, West Suffolk Hospital, Bury St Edmunds IP33 $2 Q Z$ 